\title{
CFD-DEM Analysis of Particle Attrition in a Jet in a Fluidised Bed
}

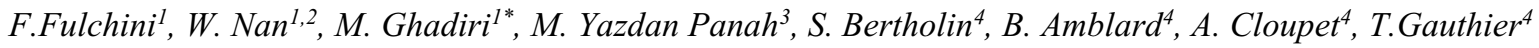 \\ ${ }^{1}$ Institute of Particle Science and Engineering, University of Leeds, Leeds, UK \\ ${ }^{2}$ State Key Labortary of Multiphase Flow in Power Engineering, Xi'an Jiaotong University, Xi' an 710049, China \\ ${ }^{3}$ TOTAL Research \& Technology Gonfreville, Le Havre, France \\ ${ }^{4}$ IFP Energies Nouvelles, Solaize, France
}

\begin{abstract}
In fluidised bed processes, the solids are in vigorous motion and thus inevitably subjected to mechanical stresses due to inter-particle and particle-wall impacts. These stresses lead to a gradual degradation of the particles by surface wear, abrasion and body fragmentation commonly termed attrition. One significant contribution of attrition comes from the air jets of the fluidised bed distributor. Particles are entrained into the air jet, where they get accelerated and impacted onto the fluidised bed particles. The jet induced attrition only affects the part of the bed which is limited by the jet length, where the mode of attrition is largely collisional. The overall jet attrition rate is therefore the result of the combination of the single particle damage and the flux of particles entering into that region. The attrition behaviour of particles in the jet region is analysed by evaluating their propensity of breakage experimentally and by simulating an air-jet in a bed of particles by CFD-DEM. The frequency of collisions and impact velocities are estimated from which the attrition due to a single air-jet is predicted.
\end{abstract}

\section{Introduction}

Circulating fluidised beds are widely used for carrying out heterogeneous reactions in which particulate solids are needed to be regenerated in order to be reprocessed. The circulation of the solids provides plenty of chances for attrition, especially where the solids meet the most stressful conditions, i.e. the gas distributors jets, bubbling bed and cyclones [1]. The jetting region is one of the most significant contributors to particle breakage. According to Zhang et al. [2] and Boerefijn et al. [3], particles can undergo different types of stresses ranging from rapid shear to impact causing surface abrasion, chipping and fragmentation depending on the orifice to particle size ratio. The orifice velocity is the influential factor for accelerating the particles and projecting them upwards, where they collide with the bed particles leading to their attrition [4]. For orifice to particle size ratios greater than about 7.5 the main mechanism of jet attrition is collisional [2, 3]. Massimilla [5] developed a hydrojet dynamic model of the flow pattern in a fluidised bed jet from which particle velocity and flux can be calculated. Coupling of such information with a single particle breakage model can give an estimation of the overall jet induced attrition as proposed by Ghadiri et al. [6] using FCC catalyst. They first evaluated the attrition propensity by single particle impact testing and then coupled it with the hydrodynamic model of the jet of Donsi et al. [7] in order to analyse the dependence of the attrition rate on the orifice velocity and size. Two fundamental aspects are recognised to contribute to the jet attrition: (i) the jet hydrodynamics which dictate the particle velocity in the jet and the rate of entrainment of the particles into it, and (ii) the particle physical properties which influence the dependence of attrition on the operating conditions. This work aims to elucidate this phenomenon by evaluating the single particle attrition propensity of Chemical Looping Combustion (CLC) oxygen carrier particles coupled with an analysis of a single submerged jet by CFD-DEM simulation.

CLC is a process developed on the circulating fluidised bed design. The particulate solids are looped between two fluidised beds, referred to as risers, in which the solids alternate chemical oxidation to chemical reduction. CLC attrition propensity is evaluated by the single particle impact test [8] and by Scirocco disperser impact test [9] for a wide range of particle impact velocities. The outcomes of the two tests are joined and a single particle attrition model is presented based on the chipping model of Ghadiri \& Zhang [10]. The CFD-DEM simulation is used to calculate process and their entrainment rate in a jet. Their coupling enables the overall attrition rate to be calculated.

\section{Materials and Method}

The material, provided by IFPEN, Solaize, France consisted of a batch of fresh natural ores manganese based CLC oxygen carriers. The particle size distribution (PSD)

\footnotetext{
* Corresponding author: M.Ghadiri@leeds.ac.uk
} 
is very wide and the particle shape very irregular as shown in Figure 1. Particle density is $3300 \mathrm{~kg} / \mathrm{m}^{3}$.

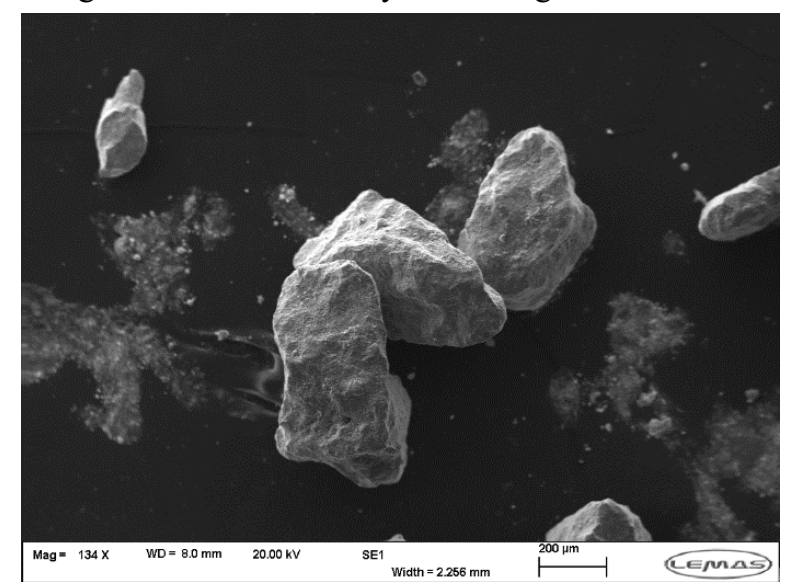

Figure 1. CLC particle analysed by Scanning Electron Microscopy (SEM)

was evaluated gravimetrically by sieving using BS sieves (as given in Table 1), so that the most representative sieve cuts of the distribution could be chosen and used to carry on single particle impact test and Scirocco disperser impact test. Therefore, the effect of particle size on breakage could be taken into account in the breakage model. The two impact tests are able to correlate the impact velocity with the extent of breakage. The extent of breakage is evaluated by gravimetric analysis: the material is collected post impact and sieved using a sieve which is two sizes below the lower limit of the feed particle cut size in order to separate the mother particles from the fines, as described below. The extent of breakage is calculated as the ratio of the mass of fines to mass of feed particles. Ghadiri and Zhang model for chipping for semi-brittle materials [10] is applied to the extent of breakage in order to determine the lumped parameter representing material properties. In parallel, the CFDDEM simulation of a single jet by EDEM ${ }^{\mathrm{TM}}$ and ANSYSFluent is carried out to evaluate the fluid-particle interactions in the jetting region. The flow of entrained particles into the jet, the number of collisions of each particle and corresponding velocity are calculated and used to estimate the overall extent of breakage.

\subsection{Particle Size Distribution}

The particle size distribution was evaluated by mechanical sieving, and reported in Figure 2. The sample was first split to get a small representative sample,

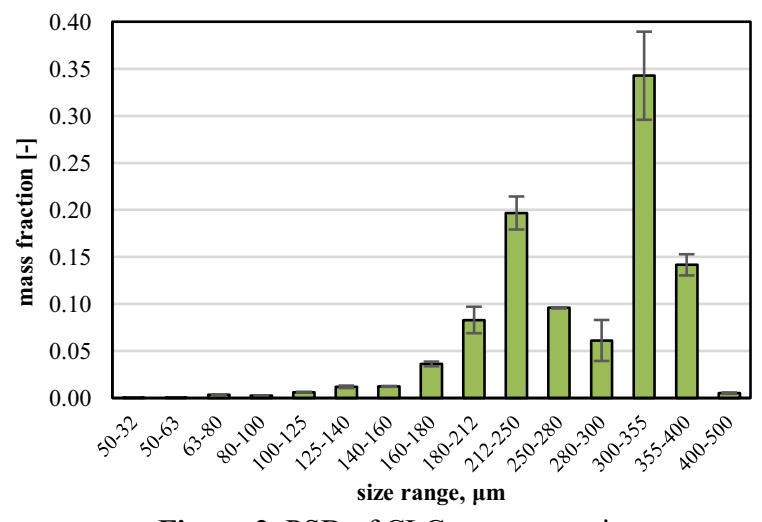

Figure 2. PSD of CLC oxygen carriers suitable for sieving, and avoiding errors due to segregation of the initial large batch [11].

Table 1. Representative size cuts used and sieve size for separating mother particles/fines for the breakage analysis

\begin{tabular}{|c|c|c|c|c|c|}
\hline $\begin{array}{c}\text { Representative } \\
\text { size cuts }(\boldsymbol{\mu m})\end{array}$ & $\begin{array}{c}180- \\
212\end{array}$ & $\begin{array}{c}212- \\
250\end{array}$ & $\begin{array}{c}250- \\
280\end{array}$ & $\begin{array}{c}300- \\
355\end{array}$ & $\begin{array}{c}355- \\
400\end{array}$ \\
\hline $\begin{array}{c}\text { Cut off sieve } \\
\text { size }(\boldsymbol{\mu m})\end{array}$ & 125 & 150 & 180 & 212 & 250 \\
\hline
\end{tabular}

\subsection{Single Particle Impact test}

The single particle impact test is according to the procedure described in [8]. Particle impact velocity is monitored and the extent of breakage is evaluated as:

$$
\mathrm{R}^{*}=\frac{\mathrm{m}_{\mathrm{D}}}{\mathrm{m}_{\mathrm{D}}+\mathrm{m}_{\mathrm{m}}} \times 100 \%
$$

where $m_{D}$ is the mass of fines and $m_{m}$ is the mass of mother particles. The velocity range achievable for this test, for CLC, goes from free fall, about $1.8 \mathrm{~m} / \mathrm{s}$, up to $26 \mathrm{~m} / \mathrm{s}$ depending on particle size.

\subsection{Scirocco Disperser Impact Test}

Scirocco is the dry disperser unit of Malvern Mastersizer 2000. Particles are fed and dispersed into an educator by a high pressure nozzle operating in the range from 0.5 to 4 barg. Given the L shaped bend of the educator, particles impact and experience attrition. Following passage through the disperser the particles are presented to the laser diffraction for the size measurement. They are recovered downstream the laser diffraction by a cyclone and analysed following the same procedure of the single particle impact test for consistency. A more detailed description is given by Ali et al. [9]. Varying the nozzle pressure from 0.5 to $4 \mathrm{barg}$, it is possible to achieve a range of impact velocity from 18 to $62 \mathrm{~m} / \mathrm{s}$ depending on the particle size.

\subsection{CFD-DEM Simulation of a Single Jet}

The single jet simulation was carried out on a very simple geometry such as a cuboid of $100 \mathrm{~mm} \times 10 \mathrm{~mm} \times 600 \mathrm{~mm}$ $\mathrm{mm}$ size. The orifice is a $5 \mathrm{~mm} \times 10 \mathrm{~mm}$ rectangular slot and placed at centre bottom of the bed. Air, at normal condition, is issued from it at $40 \mathrm{~m} / \mathrm{s}$. The particles are considered spherical, having the diameter of $925 \mu \mathrm{m}$ and the density of $3300 \mathrm{~kg} / \mathrm{m}^{3}$. The other DEM parameters such as coefficient of restitution, sliding friction and rolling friction, shear modulus and Poisson's ratio were specified as, $0.5,0.5,0.01,0.1 \mathrm{GPa}$ and 0.25 , respectively, as given by default by the softwere. The total number of particles was set as 20000 for a total bed mass of $31.97 \mathrm{~g}$. The system was simulated for $3.4 \mathrm{~s}$.

\section{Results and Discussion}

\subsection{Single Particle Impact Test and Scirocco Disperser Impact Test}

Results from the impact tests, for each size cuts, are reported below in Figure 3. The extent of breakage is plotted as a function of particle impact velocity. The extent of breakage is corrected to take account of the loss of debris and mother particles. A very small amount of 
debris is lost in the Scirocco because the collecting efficiency of the cyclone is not $100 \%$, so the extent of breakage is referred to as $\mathrm{R}^{+}$. Whilst in case of the single particle impact test, the operation of manual sieving causes some losses of mother particles. In this latter case

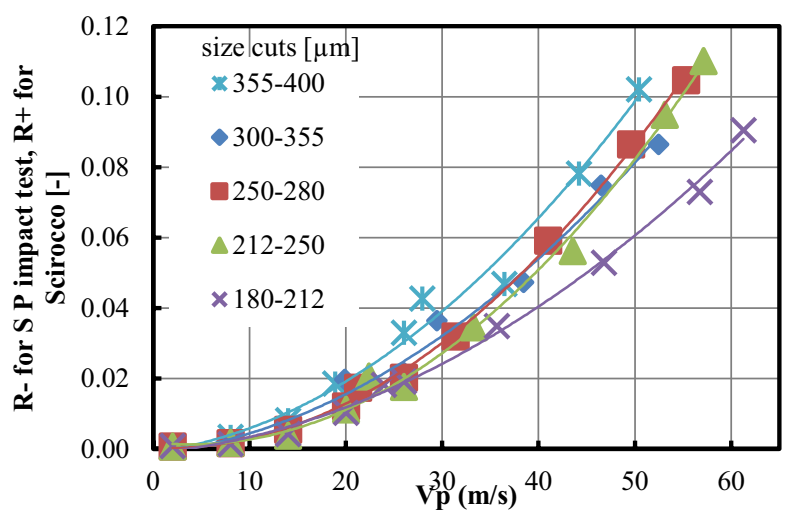

Figure 3. Gravimetric extent of breakage of CLC particles for the full range of velocities

the extent of breakage is $\mathrm{R}^{-}$. Given that the same gravimetric analysis performed for the two tests, the results are combined for the full range of particle velocities, as shown in Figure 3.

The trend is parabolic, indicating that breakage is dependent on the incident impact energy. Besides, larger particles break more than the smaller ones which is consistent with the model of Ghadiri and Zhang [10], addressed below. Applying this model to the experimental data points a unification is achieved.

$$
\mathrm{R}=\alpha \eta=\alpha \frac{\mathrm{H}}{\mathrm{K}_{\mathrm{c}}{ }^{2}} \rho \mathrm{d}_{\mathrm{p}} \mathrm{V}_{\mathrm{p}}{ }^{2}
$$

where $\rho$ is the particle density, $d_{p}$ is the particle size and $\mathrm{V}_{\mathrm{p}}$ the particle velocity. The logarithm of the extent of breakage, $\log (R)$, is plotted as a function of $\log \left(\rho d_{p} V_{p}^{2}\right)$ in Figure 4.

The slope of the straight line is a lumped parameter, representing the mechanical properties of the particle, $\alpha \mathrm{H} / \mathrm{K}_{\mathrm{c}}{ }^{2}$, where $\alpha$ is a proportionality constant, $\mathrm{H}$ is the hardness and $\mathrm{K}_{\mathrm{c}}$ is the fracture toughness. The chipping model describes very well the pattern of impact breakage. Interestingly, considering the intercept of the fitted line with abscissa, there is a minimum impact velocity for a

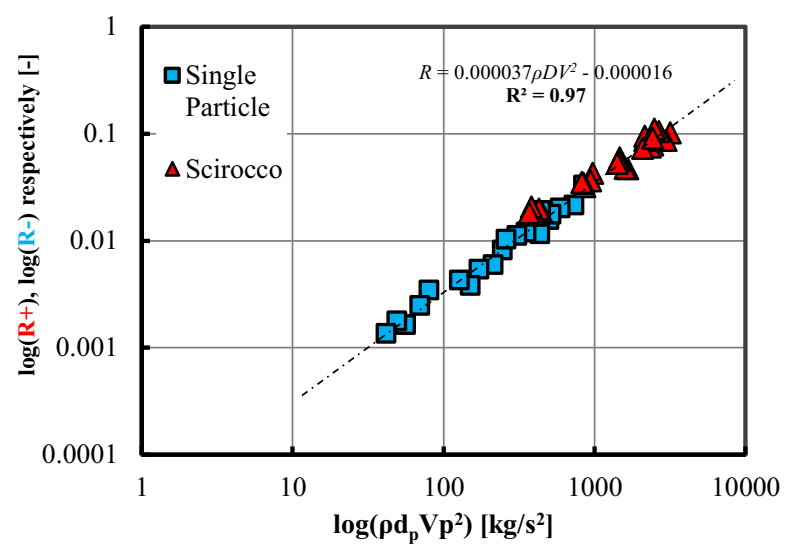

Figure 4. Extent of breakage: $\log \left(\mathbf{R}^{+}\right)$for Scirocco disperser impact test and $\log \left(\mathbb{R}^{-}\right)$for Single Particle Impact test, as a function of $\log \left(\rho \mathrm{d}_{\mathrm{p}} \mathrm{V}_{\mathrm{p}}^{2}\right)$ showing data unification

given particle size below which there is little/no breakage. The intercept can be used to estimate the transition velocity from no breakage to chipping for any particle size. In our case, considering particles of $925 \mu \mathrm{m}$, the transient velocity is $0.4 \mathrm{~m} / \mathrm{s}$.

\subsection{CFD-DEM Simulation of a Single Jet in a Fluidised Bed}

The dynamics of particle motion in the jet region was analysed in terms of particle velocity, number of collisions per particle and flux of particles into the acceleration zone. The breakage model developed in the experimental part is applied in order to estimate the overall attrition in the jet region. Particles enter the channel, created by the air jet, from the sides of the bed, Figure 5.

According to the review of Boerefijn et al. [3], in the case of large orifice to particle size ratios (5.4 in our case), particles entering the high velocity channel accelerate till they collide with the particles above the jet, experiencing attrition. The acceleration zone is limited to the channel height (about $\mathrm{z}=20 \mathrm{~mm}$ ) as it is clear from Figure 6 . Therefore, the whole analysis of attrition is limited to the jet core, where particles experience attrition by collision after they are accelerated. The breakage model of Ghadiri and Zhang was applied taking account of the flux of

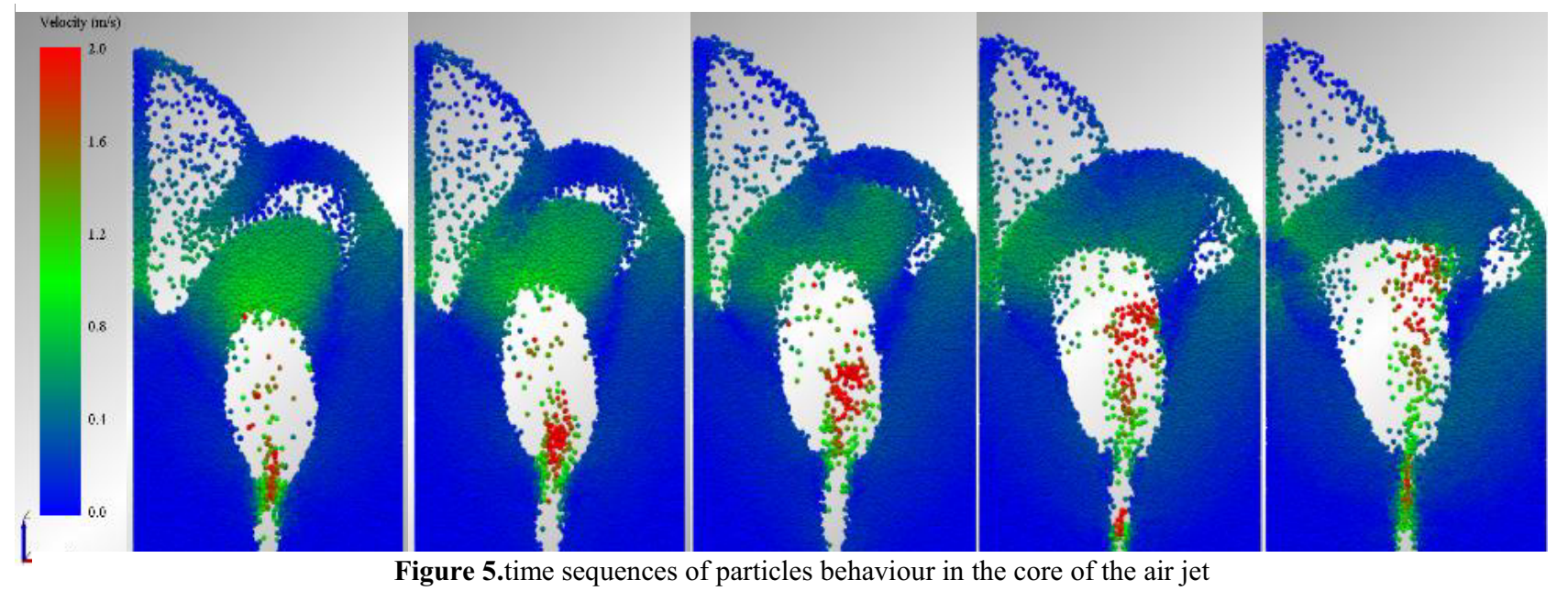




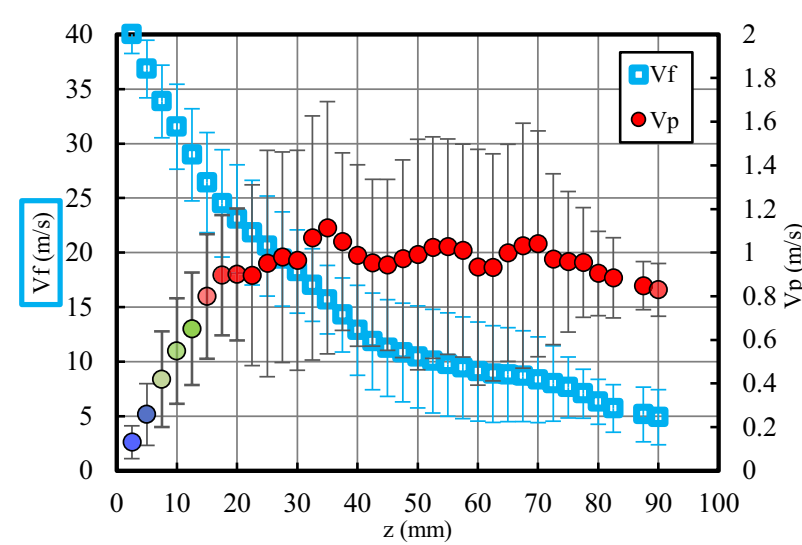

Figure 6. Time averaged air and particle velocity magnitudes at the centre bottom of the bed along $\mathrm{z}$ direction

particles entering the jet, $\mathrm{Q}$, and the number of collisions per particle, $f_{c}$, thus obtaining the breakage rate $B_{\text {jet }}$, defined as the mass of fines formed due to attrition per unit time.

$$
\mathrm{B}_{\text {jet }}=\mathrm{R} \cdot \mathrm{Q} \cdot \mathrm{f}_{\mathrm{c}}
$$

where $\mathrm{R}, \mathrm{f}_{\mathrm{c}}$ and $\mathrm{Q}$ are calculated every $0.01 \mathrm{~s}$ within the jet core, using the average impact velocity $\left(\mathrm{V}_{\mathrm{p}}\right)$, the number of particles $\left(\mathrm{N}_{\mathrm{p}}\right)$, the number of collisions $\left(\mathrm{N}_{\mathrm{c}}\right)$, the mass of single particle $\left(\mathrm{m}_{\mathrm{p}}\right)$ and $\Delta \mathrm{t}$ equal to $0.01 \mathrm{~s}$.

$$
\mathrm{Q}=\frac{\mathrm{N}_{\mathrm{p}} \cdot \mathrm{m}_{\mathrm{p}}}{\Delta \mathrm{t}} \quad \text { (4) } \quad \mathrm{f}_{\mathrm{c}}=\frac{\mathrm{N}_{\mathrm{c}}}{\mathrm{N}_{\mathrm{p}}}
$$

Table 2. Time averaged values for $\mathrm{Q}, \mathrm{f}_{\mathrm{c}}$ and $\mathrm{V}_{\mathrm{p}}$

\begin{tabular}{|c|c|c|}
\hline $\mathbf{Q}[\mathbf{g} / \mathbf{s}]$ & $\mathbf{f}_{\mathbf{c}}[-]$ & $\mathbf{V}_{\mathbf{p}}[\mathbf{m} / \mathbf{s}]$ \\
\hline 35.39 & 5.30 & 0.83 \\
\hline
\end{tabular}

In this condition, the breakage rate, i.e. the mass of debris formed by the jet per unit time, is calculated to be 0.025 $\mathrm{g} / \mathrm{s}$, which results in $0.084 \mathrm{~g}$ of mass of attrition product for the complete simulation time. At the end of the simulation, the bed inventory has therefore lost $0.26 \%$ of its mass due to the attrition of a single jet.

From the mass of fines produced, the debris size distribution of fines is calculated as follows, assuming that each impact generates only one fine particle.

$$
d_{D}=\sqrt[1 / 3]{\frac{B_{\text {jet }} \cdot d_{p}^{3}}{Q \cdot f_{c}}}
$$

The calculated particle size distribution after attrition is thus shown in Figure 7.

\section{Conclusions}

The attrition propensity of CLC particles is evaluated experimentally using two impact tests: the single particle impact test and Scirocco disperser impact test. Using the model of chipping for semi brittle material of Ghadiri and Zhang, a relationship between the extent of breakage and impact velocity is established, taking into account particle

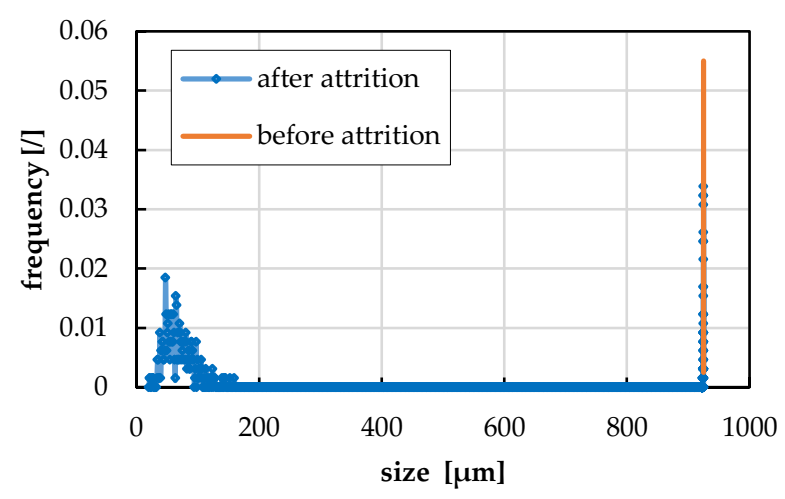

Figure 7. PSD before and after attrition

size and mechanical properties. The extent of breakage follows the square of the impact velocity and varies linearly with particle size. Particle mechanical properties such as hardness and fracture toughness were determined as a lumped parameter by plotting the extent of breakage as a function of particle density, size and velocity squared. A CFD-DEM simulation of a single jet in a fluidised bed is then performed and used to evaluate the overall attrition using the single particle breakage model and coupling it with the number of collisions per particle within the jet region and the flow of particles entering the jet core. The analysis reveals that, under these conditions, $0.025 \mathrm{~g} / \mathrm{s}$ of fines is produced by attrition and that the average debris size is about $60 \mu \mathrm{m}$. This analysis is a starting point for a more detailed and realistic approach for predicting the attrition rate, since the single particle attrition propensity can be established for any system at any conditions and coupled with $\mathrm{CFD} / \mathrm{DEM}$ to estimate the attrition rate. Validation of the simulation is planned next in order to finalise the model for a single jet.

\section{Acknowledgements}

The financial support from Total, France, is gratefully acknowledged.

\section{References}

[1] K.G. Zenz FA, Powder Bulk Technol., 4th ed., 1980: pp. $13-20$.

[2] S.-H. Zhang, R. Boerefijn, M. Ghadiri, Proc.World Congr. Part. Technol. 3, Brighton, 1998.

[3] R. Boerefijn, N.J. Gudde, M. Ghadiri, Adv. Powder Technol. 11 (2000) 145-174.

[4] T.A. Kutyavina, A.P. Baskakov, Chem. Technol. Fuels Oils. 8 (1972) 210-213.

[5] L. Massimilla, Fluid. 2, 2nd ed., Academic press, New York, 1985: pp. 133-175.

[6] M. Ghadiri, J.A.S. Cleaver, V.G. Tuponogov, J. Werther, Powder Technol. 80 (1994) 175-178.

[7] G. Donsi, L. Massimilla, L. Colantuoni, Fluidization, Matsen, New York, 1980.

[8] Z. Zhang, M. Ghadiri, Chem. Eng. Sci. 57 (2002) 3671-3686.

[9] M. Ali, T. Bonakdar, M. Ghadiri, A. Tinke, Powder Technol. 285 (2015) 138-145.

[10] M. Ghadiri, Z. Zhang, , Chem. Eng. Sci. 57 (2002) 3659-3669.

[11] J.T. Germaine, A. V. Germaine, Grain Size Analysis, in: Geotech. Lab. Meas. Eng., John Wiley \& Sons, Inc., Hoboken, NJ, USA, n.d.: pp. 84-116. 